\title{
Seafarers' depression and suicide
}

\author{
Alex Mellbye ${ }^{1}$, Tim Carter ${ }^{2}$ \\ 1ITF Seafarers' Trust, United Kingdom \\ ${ }^{2}$ Norwegian Centre for Maritime Medicine, Haukeland University Hospital, Bergen, Norway
}

\begin{abstract}
This review assesses available evidence on the frequency of and trends in depression and suicide among seafarers. Investigations of depression and suicide are scarce and the findings are inconsistent, they do, nevertheless, show indications of improvement although some recent case series do indicate that suicide remains a problem. A review of additional indicators for mental distress and lack of wellbeing supports the decline in frequency of problems, but nuances this in terms of the relative risks in different groups of seafarers, showing internal variations in the frequency of mental health issues among seafarers, with markers such as rank, type of voyage, gender, age, nationality and crew multiculturalism being relevant variables. The methodological limitations that hinder the understanding of depression and suicide in the maritime sector are identified.
\end{abstract}

(Int Marit Health 2017; 68, 2: 108-114)

\section{Key words: seafarers, depression, suicide, social isolation, burnout, deep-sea, cultural distance, selection bias, medical examinations}

\section{INTRODUCTION}

This literature review analyses recent studies of depression and suicide in seafarers. Seafarers are predominantly male, come from a variety of nations, and speak a multitude of languages. They often spend months at sea with little or no contact with their life ashore, while working and living in limited spaces where there may be substantial amounts of noise, heat and vibration as well as the motion of the ship [1]. Distance from home and the working and living environment have usually been assumed to contribute to the high suicide rate of seafarers in the past [2-7]. The question remains, however, if this is still relevant today.

A previous review of several studies up to 2009 [8], argued that it is to be expected that the high suicide rates of these earlier studies are still valid. Although (as will be discussed below) there is some evidence for this, there are also other important factors. Firstly, many of the studies included in the review noted a general declining trend in seafarer suicide rates. Secondly, most of studies are based Western European seafarers or fleets (especially from the United Kingdom), this is important given the recent trends in manning where seafarers from East Asia have become a major part of the seafarer workforce [9]. Thirdly, men as a whole are more likely to commit suicide than women $[10,11]$; therefore, some studies compared suicide rates in seafarers with male working aged populations ashore. A fourth issue with these studies which also affects much of the literature on seafarers' depression and suicide is the relevance of social isolation. Isolation is inevitable for many seafarers as they may go months without access to communication with their shore-based family and friends [12], yet how this influences them (if at all) is uncertain. A number of the published studies assume a causal relationship between isolation and suicide or depression without providing robust evidence for it.

The previous review is important as there are two apparently conflicting bodies of literature on seafarers' mental health and wellbeing; one that is troubled and perceives significant continuing morbidity as well as suicide mortality, and another that is optimistic about the available evidence on recent trends and developments. Deconstructing this debate forms the first part of this review. Having summarised the most recent evidence for seafarers' depression and suicide, the second part will discuss some important limitations to contemporary understanding and knowledge of seafarers' mental health. 
Lastly, as data on seafarers' depression and suicide is scarce and fragmented, in certain instances it is necessary to review risks indirectly using evidence on topics such as stress, fatigue, and loneliness. This is not as valid as the direct use of observations on depression and suicide, but given the lack of consistent data it is warranted, especially as there is much medical literature which indicates that factors such as stress and loneliness are related to depression and suicide [13-16].

\section{SEAFARERS' DEPRESSION AND SUICIDE}

\section{GENERAL FINDINGS}

Studies on the depression and suicide of seafarers show two opposite and contradictory trends. On the one hand there is the perception that their general mental health is by and large stable and positive. This is corroborated by such reports as The Manpower Report [17], which found that a clear majority of the sample population of seafarers reported themselves to be "satisfied", "happy", and "very happy" in response to a question about their levels of satisfaction. In an article from 2012, Oldenburg et al. [18] studied stress and burnout syndromes and found that "compared with the majority of on-shore occupations (...) the burnout risk in seafarers seems to be moderate although seafaring is repeatedly considered as a particularly demanding occupation" (my emphasis, p. 413). Similarly, Besikci et al. [19] found that fatigue and distress were not particularly pronounced in seafarers' self-reports. Other arguments for the good mental health of seafarers are the low rate of medical repatriations. From a population of 388,963 seafarers contracted from the Philippines over a 5-year period, Abaya et al. [20] found that about $1.7 \%$ had been repatriated, but that only $1.8 \%$ of these repatriations were for psychological or psychiatric reasons (about 120 seafarers or 1 in 3,000 of the population studied). This indicates that a very small proportion of seafarers become troubled enough (in psychological terms) to be returned home during their time at sea for the sake of their own mental health. Such literature makes the case that although seafaring is an occupation with hazards and risks, there is no indication of a high risk of depression.

Other reports give a contrary view. The International Transport Workers' Federation (ITF) Seafarers' Trust survey [21], for example, found that the number of seafarers who knew colleagues that had considered suicide varied from $6 \%$ to $35 \%$ of respondents, depending on their home country. Additionally, half of the sample of respondents reported often or sometimes feeling anxious, depressed and hopeless while at sea. The Women Seafarers' Health and Wellbeing Survey [22] found that the second biggest health issue for the respondents was stress, anxiety and depression. This is corroborated by a series of studies on fatigue in which it was repeatedly reported that seafarers felt tired and complained of lack of sleep [23, 24]. Finally, a study by Hjarnoe and Leppin [25] found that seafaring was associated not only with a lack of positive health behaviours (such as physical exercise) but also a presence of negative ones (such as smoking).

The picture is a complex one as many recent studies present divergent findings on the condition of seafarers' mental health and wellbeing. By contrast studies investigating seafaring risks in earlier time periods found it to be more hazardous, have a higher mortality rate, and to have had a consistently higher suicide rate than other occupations [2-7], yet many of these studies also reported a declining rate of seafarer suicide between the 1960s to the early 2000s. A more revealing picture emerges from looking at these issues within the population of seafarers i.e. which seafarers are more/less likely to become depressed or suicidal.

Looking at suicide rates from the late 1970 s to the early 2000s, Roberts and Marlow [2] concluded that "as almost $90 \%$ of suicides occurred among ratings and catering crew (...) suicide risks are strongly associated with the rank of the seafarer" (p. 179). Furthermore, about $87 \%$ of all suicides happened on large deep-sea ships. It would therefore seem as if rank and types of voyage have been important determinants of seafarers' suicide rates.

\section{RANK}

In two studies done by Oldenburg et al. $[18,26]$ there were some surprising findings. Their main conclusion was that with the exception of galley staff, officers were the most stressed rank of seafarers due to their "high responsibility for the crew and the ship and by permanently changing job demands (port clearance, district routes and watch-keeping at sea)" ([26], p. 413). This was given support in their later study which found that "officers stayed on board for considerably shorter periods (4.8 vs. 8.3 months for ratings) but had significantly more often an extremely high number of working hours (...) Correspondingly, officers complained more frequently of a higher stress level due to time pressure" ([18], p. 96). In regards to rank, it would therefore seem, on the basis of self-reported stress levels, that officers are the group which is at most risk. This is at odds with Carotenuto et al.'s study [27] which found that ratings and non-officers were more at risk for high stress levels than officers. However, their study used data from an earlier time period. The association between rank and stress (or "burnout" [26]) seems therefore to have changed over the past decade with officers being more at risk than ratings. This is supported by Allen et al. [23] who found that $61 \%$ of officers reported being "often or always affected by fatigue" ([23], p. 88). On the other hand, Thomas et al. [28] looked at the impact of seafaring on the seafarers' spouse and family 
and found that officers' families had a better relationship with the officer as s/he would have longer leave periods and so be able to spend more time at home. Comparing seafarers across their ranks, the patterns are ambiguous as officers are on one hand more stressed at work, but also seem to have stronger family and spousal relationships due to their shorter time on board.

\section{DEEP-SEA AND SOCIAL ISOLATION}

The shorter periods that officers spend at sea and its effect on relationships, as just noted, can be expected to result in reduced social isolation. In explaining why $87 \%$ of registered suicides between 1976 and 2002 happened on deep sea ships, Roberts and Marlow [2] argue that "seafarers in deep sea trading ships are often at sea continuously for weeks or months and can be exposed to isolated social and working conditions, made worse by recent reductions in ship crewing numbers, as well as long term separation from family" ([2], p. 179). More recent publications indicate a similar pattern. In listing the biggest stressors on board, a clear majority of participating seafarers reported separation from their families, and this comes before other factors such as time pressure and long working days [18, 26]. Similarly, Haka et al. [29] found that the biggest factor motivating seafarers to quit their job was "time away from home" as over $50 \%$ of their respondents reported this as their biggest issue with seafaring ([29], p. 24). Although the evidence is scarce, these studies do support the notion that separation from family and friends does indeed have a detrimental impact on seafarers' mental health with deep-sea vessels being the most susceptible for this effect.

Separation from life ashore with months spent away from home and few opportunities for communication contribute to feelings of social isolation (explicitly discussed in [12] and [8]; see also Rhode et al. [30] for isolation and loneliness and Shattell et al. [31] and Apostolopoulos et al. [32] for the social isolation of truckers). Besides direct reports of adverse effect on wellbeing other evidence gives support to the importance of social isolation as a challenge to seafarers' mental health. Seafarers' desire for better connectivity is one such factor. As reported in the Futurenautics' Crew Communications Survey of 2014 [33], 76\% of respondents identified improved internet access as the most wanted on-board service. In the ITF Seafarers' Trust survey of 2016 it was reported that $90 \%$ of respondents listed access to internet facilities as the most important of port-based welfare services [34]. Interestingly, a similar desire was voiced in The Manpower Report [17], although here it was less significant than other complaints and wishes of seafarers. A study from 2003 by Thomas et al. [28] investigated the effect of seafaring on the families of the seafarers. They found that that the length of contract (and hence time spent at sea) could have important repercussions for the family life of the seafarer, with spouses reporting loneliness during the seafarers' absence and problems in sustaining intimate and emotional relationships. Longer contract periods increased such difficulties.

The available evidence suggests that spending long periods of time at sea and away from home can have a negative effect on seafarers' mental health. Not only is there direct evidence for this in terms of self-reported stress [18, 26], but there are also other indications such Haka et al.'s [29] study on motivational factors and the reported importance of connectivity. The development of communication technology over the last ten years may have played a part in reducing the sense of distance between seafarers and their spouses, family and friends. Thus in 2007, Tang [35] noted how the internet had become a convenient way for seafarers and their partners to stay in contact and for seafarers' partners to develop a community; and it is doubtful whether access to online forums and websites has reduced since then. Although isolation is something that can be felt by all types of seafarers, evidence points to time at sea as an exacerbating factor, hence it is relevant to discuss social isolation and deep-sea voyages together.

\section{GENDER}

Women make up about 1-2\% of the world's total seafaring population [22]. The women's health and wellbeing survey reports that anxiety, stress and depression are women seafarers' second biggest reported health issue, after back/joint pain [22]. The frequency of reported back/joint pain varies with the type of job and ship but depression and anxiety are more equally distributed. This might suggest that women seafarers' health is less affected by work on different types of ship than their male counterparts'. However, when comparing women seafarers' anxiety, stress and depression with male seafarers' the predisposition of women to report these symptoms is well known from other settings [36, 37]. It needs to be noted that women seafarers also report gender related discrimination, ranging from distorted expectations of their work capacity to outright sexual harassment [38]. In addition women seafarers often have a harder time finding and retaining employment because of prejudice among employers who consider that it is better for crew morale not to have women on board as this might cause sexual tension and jealousy [39]. As women seafarers often have to deal with discrimination, one could expect to find a higher depression and suicide rate among women seafarers than in women in other less male dominated occupations [40,41].

\section{MULTICULTURALISM - AND NATIONALITY}

Multicultural and multilingual ship crews have become more common in the last 25 years. However there is little information on the contribution of these changes to seafar- 
ers' depression and suicide. There is one study that includes data on suicide in seafarers from some Asian countries and a related one on the Hong Kong fleet, both reflect incidence in the late twentieth century $[42,43]$. One study found that "cross-cultural communication on board tends to be more successful in terms of interaction and outcomes when seafarers are culturally close and less successful when they are culturally distant from each other. Cultural distance between seafarers is a major determinant of stress and leads to failure to communicate and build relationships on board. An important indicator of cultural distance is variations in pronunciation and usage of Maritime English" ([44], p. 265). Similarly, Alfiani ([45], p. 34) argues that there is a "cultural adjustment period" in which the seafarer may experience "mental pressure and psychological constraint" due to not knowing the cultural boundaries with his/her crewmates", and that speaking one's mother tongue could produce suspicion among non-speakers of that language. This may contribute to loneliness and unsatisfying social relationships, potential risk factors for depression and suicide $[13,15]$. Progoulaki $[46]$ notes the importance of 'soft' social skills to seafarers. These enable the seafarer deal with misunderstandings and potential conflicts between people of different cultures [47]. Cross-cultural conflict may arise from different values, understandings and languages and can obstruct the development of positive relationships. Although such topics as language and culture can be seen as relevant to understanding seafarers' depression and suicide, their actual impact has yet to be investigated.

\section{LIMITATIONS}

Aspects of the life and work at sea limit and may confound study findings, notably the selective factors that determine entering and maintaining a career at sea.

\section{SELECTION BIAS}

A barrier to the analysis of seafarers' depression and suicide comes from the lack of information on the characteristics of the seafaring population. The Global Seafarer [9] noted that in the 1980s there was a dramatic change in recruitment strategies for seafarers with an increasing proportion of seafarers being hired from developing countries and East Asia, particularly the Philippines. As a result, most of the new seafarers came from "non-established sources", of whom "most (...) had not previously worked on ocean-going ships" which "entailed an unavoidable reduction in standards of competence" ([9], p. 60). Similarly, Sampson ([1], p. 2) reported the same trend in recruitment and adds, "a major motivation in going to sea, and the only one for many people, is the high income that can be earned over a relatively short period of time. This is particularly true for seafarers in the developing world who, as a consequence of the globalisation of the shipping industry, can earn tremendous salaries relative to their shore-based counterparts". However this change arose from ship owners' seeking to reduce their crewing costs and seafarers from developing countries are often given lower wages than their colleagues from developed ones. As such, there can often occur a problem of exploitation, because employers pay different wages to their employees depending on nationality [46].

The increase in seafarers coming from un-established sources (which often means from poor inland areas [48]), because of the economic benefits, may be a result of a lack of employment in their area of origin. If so, then this would suggest that they are motivated go into seafaring out of necessity rather than preference. In terms of depression and suicide, this group of seafarers would therefore be expected to have a greater likelihood of having a negative reaction to the working and living conditions of seafarers, as they do not have a positive preference for this type of employment.

On the other hand there are reports that identify positive reasons for individuals going into seafaring. The Maritime Career Path Mapping [49] survey found that its respondents overwhelmingly chose a life at sea for positive reasons such as it being an "interesting and challenging job", "I like ships", and "I like travel and meeting people" (p. 14), while other reasons such as pay or lack of employment opportunities ashore ranked lower. Similarly, the importance of adventure and freedom are other themes which recur in the literature [50] along with "the possibility of seeing the world" ([51], p. 329). These studies indicate that the people who go into seafaring may do so through interest and choice rather than economic necessity. In this case one would expect the population of seafarers to have a very different reaction to the work conditions of seafaring than those who work at sea solely for economic reasons.

In terms of understanding seafarers' depression and suicide, one can think of these differences in attitude as variables that can be activated depending on conditions on board. One would, for instance, expect the wellbeing of a seafarer who comes from poverty and provides for his/her family as more likely to have a more negative response to being repatriated from a ship after an injury than a seafarer with a financially secure background and who has no family responsibilities. The role that a seafaring career plays in a person's life depends on their situation and attitudes, thus one can never fully assess the topic of depression and suicide among seafarers without taking into account the wider context of their situation when working at sea.

The variables just described could be termed sociological, but there are also important psychological ones that need to be considered. Most important is the lack of access to information about seafarers' mental health records. As long as this is missing it is difficult to make robust assess- 
ments of the contributory causes of seafarer depression and suicide, as the contributions of pre-boarding mental health issues and events arising while at sea will be obscure. The recruitment of seafarers may also affect risk, those with mental health problems may choose not to work at sea or be denied employment, but conversely individuals with mental health issues such as depression may be attracted to a career at sea due to its isolation and distance from society. Gould [52] reported that some seafarers perceived seafaring as an attractive escape from troubles. Because of all these potential confounding factors a better understanding of recruitment into work at sea is a pre-condition for improved analysis of the role of life at sea as a cause of depression and suicide.

\section{MEDICAL EXAMINATIONS AND HEALTH ASSESSMENTS}

Ideally, workers and employers in any occupation should be able to have trust in a mutually beneficial health care service that assures the employer of fit workers and the workers of appropriate medical service without loss of employment. This is not always the case in the seafaring world. Pre-employment medical examinations (PEMEs) are medical examinations intended to assess whether or not the seafarer is fit enough for work. If $s /$ he is then $s / h e$ will be given a medical certificate qualifying him/her for work on board a ship [53]. All seafarers are required to successfully complete these in order to sign a contract for a voyage. A few issues occur: Firstly, the assessments are primarily focused on investigating physical health and are therefore less likely to find mental health problems such as depression, not least because mental health problems are inherently difficult to detect. Secondly, because seafarers are dependent on the certificates to obtain a contract and hence income, there have been problems with seafarers using falsified certificates [46]. Thirdly, there is the issue of who has access to the results of the medical examination. As Carter et al. [54] writes, "medical information needs to be held in confidence by the examining doctor who issues a certificate of fitness, especially when this is issued directly to the employer or crewing agent rather than being handed to the seafarer. This prevents employers and agents second guessing decisions on the certification of fitness, and hence who to offer employment to, by forming their own views on the clinical findings" ([54], p. 1-2). Thus the PEME is by itself not suited for detecting mental health issues such as the risk of depression and suicide, with the added problem that there is a significant potential for conflict of interests between seafarers and their employers [55]. Employers want fit and healthy (i.e. low-risk) seafarers on their ships, while seafarers will often want employment (and may even be financially dependent on employment) regardless of their health.
A similar conflict of interests also relates to seafarers' access to health care. As one survey found, concerns about confidentiality are one of the biggest obstacles to seafarers seeking health care [22]. Similarly, another study found that a majority of seafarers pursue health care through private health care organisations that are unrelated to the seafaring world [56]. The potential conflict of interests between seafarers and their employers over the role of health care and health assessments may mean that there are limitations to the scope for detecting seafarers' depression and suicide risks in the course of clinical contacts, perhaps the one exception being data on repatriation rates [20].

\section{FURTHER CHALLENGES}

Some of the problems in assessing risks are more general and relate to the industry as a whole, as they are a consequence of seafarers spending long periods at sea and moving across international borders. This imposes limitations for research, as the only seafarers who can respond to surveys are the ones with access to internet, which is often only available when ashore. Furthermore, longitudinal studies are difficult to conduct due to the mobile nature of the seafaring profession. International surveys are also complicated by the need to conduct them in more than one language and to recognise that cultural understandings of what it means to be depressed or suicidal vary widely, thus adding to the difficulty of producing good cross-cultural data representations of seafarers' mental health. As Fernando [57] writes, "there are fundamental differences between concepts of mental health and mental disorder derived from Western cultures and those from non-Western cultures in Asia, [and] Africa (...) differences that continue to exist in spite of the so-called "Westernisation of the world" ([57], p. 67). Furthermore, there is very little information about seafarers' life once home and ashore ((Thomas et al. [28] is an exception). As seafarers are employed on the basis of voyages, information on depression and suicides once ashore would be recorded in national health databases that are not readily accessible to the maritime health investigator.

As a consequence of these complexities much of what is known is derived from case series with limited ability for generalisation $[6,19,25]$. The few surveys that have been conducted in recent years and which address aspects of mental wellbeing (such as $[17,21,22$, 49]) have inconsistent findings.

Another complication in assessing risks of depression and suicide are 'disappearances'. These are seafarers who are presumed to have fallen overboard and drowned. These are usually assumed to be accidents, though the possibility that they are homicides and suicides cannot be excluded [5]. A previous study [2] noted that that suicide was considered the probable cause in most disappearances at sea. This would suggest that the reporting of suicides is often but 
not always biased towards underreporting. Some reports include disappearances at sea as suicides; and bodies later found drowned - with "open verdicts" subsequently recorded as accidents. One can therefore assume that ships or fleets that report a high frequency of disappearances could have a more serious problem with suicide than that indicated by official suicide statistics.

\section{CONCLUSIONS}

Contemporary evidence that relates to seafarers' depression and suicide is scarce and fragmented. This has made it necessary to somewhat broaden the scope of inquiry by investigating such topics as stress and loneliness. Once this is done, the general conclusion is that, while seafarers have had severe problems with mental health in the past, the trend appears to be improving. This is corroborated by (a) articles which have either noted a declining trend in suicides or the lack of dramatic stress levels in contemporary seafarers as compared to onshore occupations, and (b), the lack of studies which definitely indicate a high rate of depression and suicide (to the best of the authors' knowledge, the ITF report and Women Seafarers' Health and Wellbeing survey are the only two contemporary studies that provide direct evidence). Overall there is nothing to suggest that such reassuring conclusions are valid for all seafarers or for all seafaring activities as the pattern of risks and responses is complex. For example a consistent finding is that there are significant variations in mental health between different sub-groups of the seafaring population. Much attention has been given to the contribution of social isolation, and taken together with related variations associated with rank and type of voyage, this appears to be important. For example, ratings on deep-sea voyages are more likely to suffer from long-term stress and loneliness when compared to officers who have more frequent shore leave and short but intensive periods of work at sea. Additionally, women may experience seafaring differently from men in that they have to deal with gender discrimination in addition to all the other strains of the job. It is variations in mental health relating to rank and gender that require closer study in order to identify optimal policies for reducing the risks of depression and suicide amongst seafarers.

\section{ACKNOWLEDGEMENTS}

This review was originally prepared as a background paper for an ITF Seafarer's Trust expert workshop on social isolation, depression and suicide held in autumn 2016. Alex Mellbye was commissioned to prepare the paper while employed by the Trust. Tim Carter participated in the workshop and in the preparation of a report summarising its conclusions (in press). Kimberly Karlshoej, the head of the Trust, supported the preparation of this review.

\section{REFERENCES}

1. Sampson H. International seafarers and transnationalism in the twenty first century. Manchester University Press 2013: Manchester.

2. Roberts SE, Marlow PB. Traumatic work related mortality among seafarers employed in British merchant shipping, 1976-2002. Occup Environ Med. 2005; 62(3): 172-180, doi: 10.1136/ oem.2003.012377, indexed in Pubmed: 15723882.

3. Roberts SE, Jaremin B, Lloyd K. High-risk occupations for suicide. Psychol Med. 2013; 43(6): 1231-1240, doi: 10.1017/ S0033291712002024, indexed in Pubmed: 23098158.

4. Roberts SE, Nielsen D, Kotłowski A, et al. Fatal accidents and injuries among merchant seafarers worldwide. Occup Med (Lond). 2014; 64(4): 259-266, doi: 10.1093/occmed/kqu017, indexed in Pubmed: 24671028.

5. Roberts SE, Carter T. Mortality from accidents, disease, suicide and homicide in the British fishing industry from 1900 to 2010. Int Marit Health. 2015; 66(4): 211-219, doi: 10.5603/IMH.2015.0042, indexed in Pubmed: 26726892.

6. Szymanska K, Jaremin B, Rosik E. Suicides among Polish seamen and fishermen during work at sea. International Maritime Health. Intl Marit Health. 2006; 5 7(1-4): 36-45.

7. Oldenburg M, Herzog J, Harth V. Seafarer deaths at sea: a German mortality study. Occup Med (Lond). 2016; 66(2): 135-137, doi: 10.1093/occmed/kqv153, indexed in Pubmed: 26409049.

8. Iversen RTB. The mental health of seafarers. Int Marit Health. 2012; 63(2): 78-89, indexed in Pubmed: 22972547.

9. Bloor T, Kahveci M. The Global Seafarer: Living and working conditions in a globalized industry. International Labour Office 2004: Geneva.

10. Canetto SS, Sakinofsky I. The gender paradox in suicide. Suicide Life Threat Behav. 1998; 28(1): 1-23, indexed in Pubmed: 9560163.

11. Orszag, P, R. 2014. Why Do Men Commit More Suicide. https:// www.bloomberg.com/view/articles/2014-08-20/why-do-moremen-commit-suicide (2014).

12. Swift, 0. 2015. Social Isolation of Seafarers; What is it? Why does it matter? What can be done? International Seafarers Welfare and Assistance Network. http://seafarerswelfare.org/news-and-media/ latest-news/article-discusses-the-social-isolation-of-seafarers.

13. Stravynski A, Boyer R. Loneliness in relation to suicide ideation and parasuicide: a population-wide study. Suicide Life Threat Behav. 2001; 31(1): 32-40, indexed in Pubmed: 11326767.

14. Hammen C. Stress and Depression. Annual Review of Clinical Psychology. 2005; 1(1): 293-319, doi: 10.1146/annurev.clinpsy.1.102803.143938.

15. Heinrich LM, Gullone E. The clinical significance of loneliness: a literature review. Clin Psychol Rev. 2006; 26(6): 695-718, doi: 10.1016/j.cpr.2006.04.002, indexed in Pubmed: 16952717.

16. Nock MK, Hwang I, Sampson NA, et al. Mental disorders, comorbidity and suicidal behavior: results from the National Comorbidity Survey Replication. Mol Psychiatry. 2010; 15(8): 868-876, doi: 10.1038/ mp.2009.29, indexed in Pubmed: 19337207.

17. The BIMCO and ICS Manpower Report. Published by Maritime International Secretariat Services Limited. 2015.

18. Oldenburg M, Jensen HJ, Wegner R. Burnout syndrome in seafarers in the merchant marine service. Int Arch Occup Environ Health. 2013; 86(4): 407-416, doi: 10.1007/s00420-012-0771-7, indexed in Pubmed: 22526089.

19. Beşikçi EB, Tavacıoğlu L, Arslan Ö. The subjective measurement of seafarers' fatigue levels and mental symptoms. Maritime Policy \& Management. 2015; 43(3): 329-343, doi: 10.1080/03088839.2015.1047426. 
20. Abaya AR, Roldan S, Ongchangco JC, et al. Repatriation rates in Filipino seafarers: a five-year study of 6,759 cases. Int Marit Health. 2015; 66(4): 189-195, doi: 10.5603/IMH.2015.0038, indexed in Pubmed: 26726888.

21. A Broader Vision of Seafarer Wellbeing: Survey of ITF Maritime Affiliates on HIV/Aids, Health and Wellbeing. http://www.itfglobal. org/media/819789/hiv_survey.pdf (2015).

22. The Women Seafarers' Health and Wellbeing Survey, 2015. Seafarers Hospital Society. http://seahospital.org.uk/wp-content/ uploads/2015/10/women-seafarers-health-and-welfare -survey-1-1.pdf (2015).

23. Allen $P$, Wadsworth $E$, Smith A. Seafarers' fatigue: a review of the recent literature. Int Marit Health. 2008; 59(1-4): 81-92, indexed in Pubmed: 19227741.

24. Wang H. Study on the assessment of seafarers' fatigue. World Maritime University 2012: Sweden.

25. Hjarnoe L, Leppin A. A risky occupation? (Un)healthy lifestyle behaviors among Danish seafarers. Health Promot Int. 2014; 29(4): 720-729, doi: 10.1093/heapro/dat024, indexed in Pubmed: 23630132.

26. Oldenburg M, Jensen HJ, Latza U, et al. Seafaring stressors aboard merchant and passenger ships. Int J Public Health. 2009; 54(2): 96-105, doi: 10.1007/s00038-009-7067-z, indexed in Pubmed: 19288290.

27. Carotenuto A, Molino I, Fasanaro AM, et al. Psychological stress in seafarers: a review. Int Marit Health. 2012; 63(4): 188-194, indexed in Pubmed: 24595974.

28. Thomas M, Sampson H, Zhao M. Finding a balance: companies, seafarers and family life. Maritime Policy \& Management. 2003; 30(1): 59-76, doi: 10.1080/0308883032000051630.

29. Haka M, Borch DF, Jensen C, et al. Should I stay or should I go? Motivational profiles of Danish seafaring officers and non-officers. Int Marit Health. 2011; 62(1): 20-30, indexed in Pubmed: 21534222.

30. Rohde N, D'Ambrosio C, Tang K, et al. Estimating the Mental Health Effects of Social Isolation. Applied Research in Quality of Life. 2015; 11(3): 853-869, doi: 10.1007/s11482-015-9401-3.

31. Shattell M, Apostolopoulos Y, Sönmez S, et al. Occupational stressors and the mental health of truckers. Issues Ment Health Nurs. 2010; 31(9): 561-568, doi: 10.3109/01612840.2010.488783, indexed in Pubmed: 20701418.

32. Apostolopoulos Y, Sönmez S, Hege A, et al. Work Strain, Social Isolation and Mental Health of Long-Haul Truckers. Occupational Therapy in Mental Health. 2016; 32(1): 50-69, doi: 10.1080/0164212x.2015.1093995.

33. Futurenautics Research: The Crew Communications Survey. 2014. Futurenautics. http://www.futurenautics.com/download/thecrew-communications-survey-2014-3/.

34. Norman and Mellbye, 2017. The ITF Seafarers' Trust Port-Based Welfare Services Survey 2016: Summary Report. ITF Seafarers' Trust. http://www.seafarerstrust.org/the-itf-seafarers-trust-portbased-welfare-services-survey-2016-summary-report/.

35. Tang L. 2007. Coping with separation: Chinese seafarer-partners in cyberspace. Seafarers International Research Centre. http://www. sirc.cf.ac.uk/uploads/publications/Tang.pdf.

36. Albert PR. Why is depression more prevalent in women? J Psychiatry Neurosci. 2015; 40(4): 219-221, doi: 10.1503/jpn.150205, indexed in Pubmed: 26107348.

37. Rosch PJ. 2014. Why do women suffer more from depression and stress? The American Institute of Stress. http://www.stress.org/ why-do-women-suffer-more-from-depression-and-stress/.

38. Alagbe J. 2016. Female seafarers' shocking revelation: to our bossare just sex tools. The Punch. http://punchng.com/femaleseafarers-shocking-revelation-bosses-just-sex-tools/.
39. Thomas M. 'Get yourself a proper job girlie!': recruitment, retention and women seafarers. Maritime Policy \& Management. 2004;31(4):309-318, doi: 10.1080/0308883042000259828.

40. Vision Critical, 2013. Attitudes in the Workplace: a study of sexism and discrimination in Britain. https://www.worldpayzinc.com/attitudes-in -the-workplace.pdf.

41. Martin P, Barnard A. The experience of women in male-dominated occupations: A constructivist grounded theory inquiry. SA Journal of Industrial Psychology. 2013; 39(2), doi: 10.4102/sajip.v39i2.1099.

42. Nielsen D. Deaths at sea - a study of fatalities on board Hong Kong-registered merchant ships (1986-95). Safety Science. 1999; 32(2-3): 121-141, doi: 10.1016/s0925-7535(99)00016-8.

43. Nielsen $D$, Roberts $S$. Fatalities among the world's merchant seafarers (1990-1994). Marine Policy. 1999; 23(1): 71-80, doi: 10.1016/s0308597x(98)00017-7.

44. Ioana VR. 2013. Teaching intercultural communication skills or how to become a cross- culturally intelligent seafarer. http://iamu-edu.org/ wp-content/uploads/2014/07/TEACHING-INTERCULTURAL-COMMUNICATION-SKILLS-OR-HOW-TO-BECOME-A-CROSS-CULTURALLY-INTELLIGENT-SEAFARER.pdf.

45. Alfiani DS. 2010. Multinational and multicultural seafarers and MET students : a socio-cultural study for improving maritime safety and the education of seafarers. World Maritime University. http://commons. wmu.se/cgi/viewcontent.cgi?article=1424\&context=all_dissertations.

46. Progolulaki, 2011. DEALING WITH THE CULTURE OF THE MARITIME MANPOWER INASOCIALLYRESPONSIBLE MANNER. http://www.he-alert. org/filemanager/root/site_assets/standalone_article_pdfs_0605-/ he00755.pdf.

47. Ion A. 2002. Cultural diversity on board ships. Universitate Pentru Comunitate. http://www upm ro/ldmd/LDMD-02/Pol/Pol (2002).

48. Zhao M, Amante M. Chinese and Filipino Seafarers: A Race to the Top or the Bottom? Modern Asian Studies. 2005; 39(03): 535, doi: 10.1017/ s0026749x04001660.

49. Maritime Career Path Mapping. 2013. Nautilus International. https:// www.nautilusint.org/media/169249/ETF-ECA-Maritime-Career-mapping-2013.pdf.

50. Ljung, M; and Widell, G. 2014. Seafarers`' working career in a life cycle perspective - driving forces and turning points. University of Gothenburg. http://www.gu.se/english/research/publication/?publicationld=204970.

51. Arsenie, P; Hanzu-Pazara, R; and Surugiu, F. 2014. Recruitment and Retention of Seafarers - what calls to and keeps individuals in a career at sea? International Association of Maritime Universities. http://iamu-edu. org/wp-content/uploads/2014/07/ (2014).

52. Gould EA. 2010. Towards a total occupation: A study of UK Merchant Navy Officer cadetship. ORCA. http://orca.cf.ac.uk/55023/.

53. Guidelines on the medical examinations of seafarers. 2013. International Labour Office. http://www.ilo.org/sector/Resources/codes-of-practice -and-guidelines/WCMS_174794/lang-en/index.htm.

54. Carter T, Siegel B, Mead H, et al. Who should profit from the business of science? Public money, private gain, profit for all. Hastings Cent Rep. 1987; 17(3): 5-7, doi: 10.5603/imh.2016.0001, indexed in Pubmed: 3610628.

55. Kahveci E. 1999. FastTurnaround Ships and Their Impact on Crews. Harbour Agency Limited. http://www.harbour-maritime.com/downloads.html.

56. MacCalman L., Shafrir A., Cowie H., Crawford J., Ritchie P. 2011. Health care needs and access to health care among merchant seafarers and fishermen of working age based in the UK. Seafarers Hospital Society. http://seahospital.org.uk/wp-content/uploads/2015/10/Seafarers-Study-Report-August-20111.pdf.

57. Fernando S. Mental Health, Race, and Culture. 2nd Ed. Palgrave MacMillan, Basingstoke 2002: Basingstoke. 